\title{
Use of pH-thermosensitive hydrogels for nickel ion removal and recovery
}

\author{
Álvarez Casillas Cesar Andrés ${ }^{1}$ and Cortés Ortega Jorge Alberto ${ }^{1 *}$ \\ ${ }^{1}$ Departamento de Química, Universidad de Guadalajara, Guadalajara, Jalisco, México \\ *jorcortes@hotmail.com
}

\begin{abstract}
$\mathrm{N}$-isopropylacrylamide / itaconic acid hydrogels were prepared in this study, varying the proportion of itaconic acid in the pregel mixture. The kinetics of the hydrogel swelling at $4{ }^{\circ} \mathrm{C}$ was determined, obtaining the kintetic patameters, in accordance with the second-order kinetic model. Similarly, the capacity to absorb water in terms of temperature was determined, along with the transition temperature of the samples. The influence of temperature on the capacity of the hidrogels to absorb nickel from aqueous solutions at $5 \%$ of $\mathrm{NiCl}_{2}$ and its subsequent recuperation was determined.
\end{abstract}

Keywords: hydrogels, metals remover, recovery metals, $p H$-sensitive, thermosensitive.

\section{Introduction}

Over recent years, the remediation of water contaminated with heavy metals has been carried out through the application of various methods ${ }^{[1-6]}$, using both chemical and physical processes. Various studies have analyzed the possibility of using hydrogels for the retention and removal of heavy metals from contaminated wate ${ }^{[7-11]}$, reporting good results in terms of the removal process. However, there is no information available on either a process for recovering heavy metals from used polymer matrixes or the possible reuse of these matrixes. The costs of the remediation of contaminated water can be reduced through matrix reuse, provided that the material used for the removal of the metals is, as with the metals recovered during various inductrial processes. Poly(N-isopropylacrylamide) (NIPA) is a thermo- responsive polymer that has a lower critical solution temperature (LCST) of $32{ }^{\circ} \mathrm{C}^{[12]}$ in water. Below the LCST ${ }^{[13,14]}$, polyNIPA and water are completely miscible; above the LCST, phase separation occurs. As a consequence of this transition, crosslinked polyNIPA hydrogels exhibit a volume phase transition at around to this value. This temperature is known as the volume phase transition temperature $\left(\mathrm{T}_{\mathrm{TVP}}\right)$, which is characterized by a sudden decrease in the capacity to absorb water and occurs at around $32{ }^{\circ} \mathrm{C}$. The addition of acid groups to the NIPA polymer chain has been found to increase both the capacity to absorb water and raise the transition temperature ${ }^{[15]}$. Therefore, this study aims to analyze the possibility of using thermosensitive and $\mathrm{pH}$-sensitive hydrogels for the removal and recovery of nickel ions from aqueous solutions, by placing the hydrogels in aqueous nickel solutions at below transition temperature, and, once equilibrium is attained, raising the temperature to above $\mathrm{T}_{\mathrm{TVP}}$, in order to recover the nickel removed.

\section{Materials and Methods}

\subsection{Materials}

$\mathrm{N}$-isopropylacrylamide (NIPA) with a purity of $99 \%$, from Aldrich. Itaconic acid (IA) with a purity of $99 \%$, from Aldrich. The initiator used was potassium peroxydisulfate $\left(\mathrm{K}_{2} \mathrm{~S}_{2} \mathrm{O}_{8}\right)$,

at $99 \%$ purity, from Aldrich. N,N, methylenebisacrylamide (NMBA) was used as a cross-linking agent with a purity of $99 \%$ (TCI). The accelerator used was N, N, N, N, tetramethylenediamine (TMEDA) from Tokyo Kasei. Bidistilled water was used in all the experiments.

\subsection{Synthesis of hydrogels}

Aqueous monomer solutions to 10 percent by mass (NIPA and IA, modifying the proportion of acid) were prepared in $20 \mathrm{~mL}$ glass containers in nitrogen atmosphera, to which was added $1 \%$ cross-linking agent in relation to the monomers, as well as $\mathrm{NaOH}$ solution for the complete neutralization (stoichiometric ratio) of the acid content of each sample. Once the solution had been formed, nitrogen was bubbling for one minute, $2 \%$ of initiator and $3 \%$ of accelerator was added in relation to the monomers (ensuring that all samples had a final monomer/water ratio of 10/90), the container was closed and sealed with parafilm, and left to react for 24 hours at $25^{\circ} \mathrm{C}$. The diagram of the polymerization reaction is shown in Figure 1

\subsection{Cleaning}

Once the reaction had finished, the samples were left to dry, firstly for three days at room temperature and then in a vacuum oven at $40{ }^{\circ} \mathrm{C}$. This was carried out to avoid rupturing the samples due to sudden drying. The dry samples are placed in distilled water at $25^{\circ} \mathrm{C}$ and, once they have attained equilibrium swelling (at around 7 days) $)^{[11]}$, they are placed in a temperature controlled bath at $40^{\circ} \mathrm{C}$ for 2 days to remove from the samples the material that had not been added to the network. The water was then changed and the process repeated, until no signs were observed of turbitity in the wash water at $40{ }^{\circ} \mathrm{C}$. The turbidity of wash water is an indicator of the presence of monomers and oligomers that contain NIPA. Once the process had been completed, the samples were left to dry, as described above, with their weight before and after the cleaning process used to determine the conversion level during the polimerization reaction. 


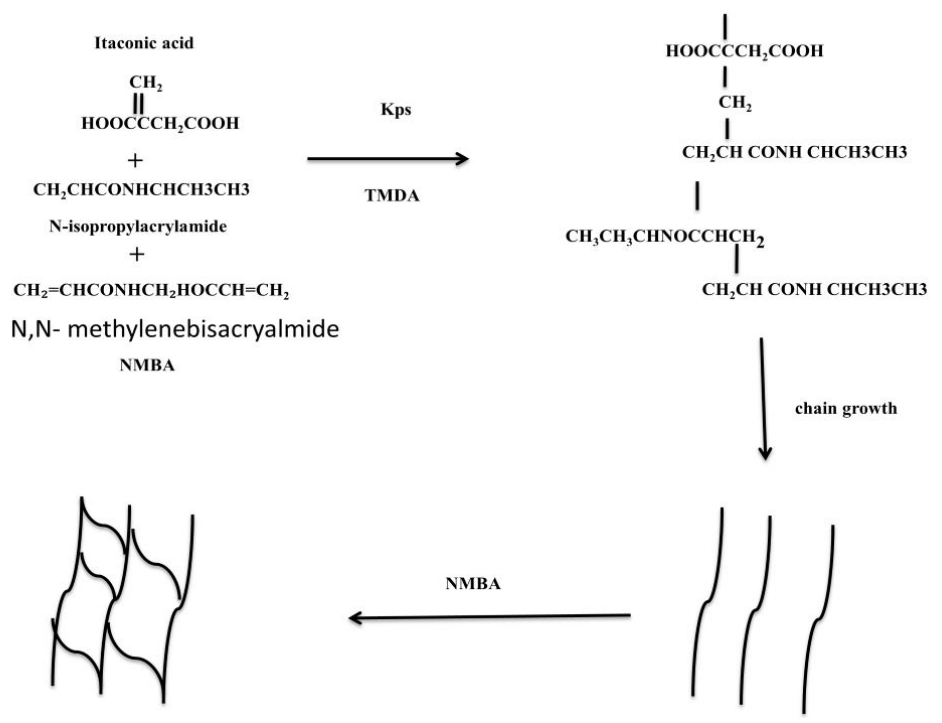

Figure 1. Scheme of the polymerization reaction of the synthesized hydrogels.

\subsection{Swelling kinetics}

To determine the swelling kinetics, the dry samples are weighed and placed in water at $4{ }^{\circ} \mathrm{C}$. The samples are weighed at different times, with their surface dried using absorbent paper. The swelling kinetics are determined using the difference between the weight of the dry and swollen sample. This process is repeated until the weight of the swollen sample does not change, which determines the equilibrium swelling $(\mathrm{H} \infty)$, to the temperature of the experiment, with the swelling determined by means of the following equation ${ }^{[16]}$ :

$H=\frac{m_{t}-m_{0}}{m_{0}}=\frac{\text { weight of hydrogel }- \text { weight of xerogel }}{\text { weight of xerogel }}$

\subsection{Equilibrium swelling in relation to temperature}

Once the samples attained the equilibrium swelling at $4{ }^{\circ} \mathrm{C}$, the samples were placed in a controlled temperature bath at $30^{\circ} \mathrm{C}$ and, once they had reached the equilibrium swelling (which was determined using the process described above), the temperature was raised. The temperatures used in this study ranged from 4 to $46^{\circ} \mathrm{C}$. The transition temperature $\left(\mathrm{T}_{\mathrm{TVP}}\right)$ was determined using the equilibrium swelling curves versus the temperature, measuring the change in the water content in terms of equilibrium and temperature.

\subsection{Nickel absorbing capacity}

The xerogels are placed in 5\% nickel (II) chloride aqueous solutions at $4{ }^{\circ} \mathrm{C}$ until the equilibrium swelling is reached (the time is determined by the swelling kinetics obtained previously) (a ratio of 300 grams of solution was used per gram of xerogel, for all experiments). Once this occurred, the samples were withdrawn from the medium and weighed, and a sample then taken from the residual solution to determine the concentration of $\mathrm{Ni}^{+2}$. Using the Genesys 10 U.V. spectrophotometer from the Thermoelectron Corporation, the samples are returned to the solution and placed in a controlled temperature bath at $30^{\circ} \mathrm{C}$, upon which the process described above is repeated, the temperature of the bath is raised to $40{ }^{\circ} \mathrm{C}$, and the quantity of nickel removed is determined. This process is repeated for solutions with a $\mathrm{pH}$ of 3 (which is regulated by adding $\mathrm{HCl}$ ) and a $5 \%$ $\mathrm{NiCl}_{2}$ weight. All experiments were carried out in systems without agitation.

\section{Results and Discussions}

Swelling kinetics has been studied by various authors using the following equation ${ }^{[17-19]}$ :

$$
\frac{d W}{d t}=K\left(W_{\infty}-W\right)^{2}
$$

Where:

$$
W=\frac{m_{t}-m_{0}}{m_{t}}=\frac{\text { weight of hydrogel }- \text { weight of xerogel }}{\text { weight od hydrogel }}
$$

Which, on being integrated with $\mathrm{W}=0$ in $\mathrm{t}=0$, the following was obtained:

$$
W=\frac{K W_{\infty}^{L} t}{1+K W_{\infty} t}
$$

On combining Equations 1-3, the following was obtained:

$$
\frac{t(H+1)}{H}=\frac{\left(H_{\infty}+1\right)^{2}}{K H_{\infty}^{2}}+\frac{H_{\infty}+1}{H_{\infty}} t
$$

Which is rearranged as:

$$
\frac{t(H+1)}{H}=m t+b
$$

With which $\mathrm{H}$ can be obtained in relation to time, with the following equation: 


$$
H=\frac{t}{t(m-1)+b}
$$

With this expression, it is possible to determine the kinetic parameters with which the speed of water absorption and equilibrium swelling are obtained. Figure 2 shows the comparison between the experimental data and the theoretical prediction obtained with Equation 7, in which a good description of the experimental data is observed, thus confirming the standard deviation between the experimental data and the theoretical prediction, with said deviation presented in Table 1.

Transition temperature is determined by calculating the change in equilibrium swelling in relation to the temperature, with the temperature at which this change acquires the absolute maximum value being determined as the transition temperature (Table s1 of Supplementary material). The kinetic parameters and the equilibrium swelling are presented in Table 1. It can be observed that, on increasing the concentration of itaconic acid, the capacity of the hydrogels to absorb water increases (Figure 3), The yield obtained from the polymerization reaction of the samples was greater than $98 \%$ in all cases, as does the transition temperature of the samples (Figure 4 and Figure s1 of Supplementary material). This is due to the increase of the carboxylic groups, which, in turn, increases the hydrophile groups, thus absorbing a greater amount of water ${ }^{[15,19,20]}$.

Table 2 shows the decrease in the capacity of the hydrogels to absorb nickel solutions in relation to the capacity to absorb water, which is explained by the interactions of the nickel ions with the carboxylic groups, avoiding the association between the water molecules and these groups, reducing the capacity to absorb solution from the hydrogels. Similar results have been previously reported ${ }^{[21]}$, from which it is possible to speculate on the benefits of adding hydrogels, instead of xerogels, to the nickel solutions in order to determine whether the capacity to absorb ions increases. In the hydrogels, the polymer chains are found to be extended, while the xerogel chains expand. The risk of elongating the chains to their maximum length could be reduced or avoided, depending on the quantity of solution that is being penetrated and the presence of nickel ions. On the other hand, it is possible to establish the nickel removal process depending on the prevailing climate in the area from where the water to be decontaminated is found, with the hydrogels (or xerogels) placed at low (lower than $10^{\circ} \mathrm{C}$ ) or medium temperatures (higher than $15^{\circ} \mathrm{C}$ ). For the recovery of the nickel removed, the loaded gels can be placed at greater temperatures for those hydrogels with a lower itaconic acid content in the matrix, while those hydrogels that have a greater proportion of itaconic acid are placed in $\mathrm{pH} 3$ solutions and greater temperatures.

In this regard, an analysis must be undertaken of the minimum amount of solution with a $\mathrm{pH}$ of between 3 and 1 (taking into account of the possible degradation of material) that must be added to provoke the deswelling of the hydrogel and the amount of recovered nickel. It

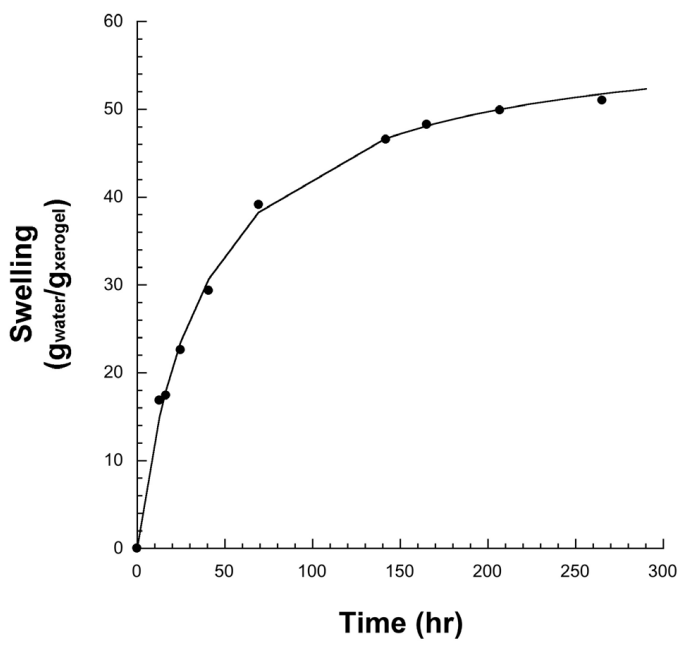

Figure 2. Comparison between experimental data and the second order swelling kinetic model for the NIPA/IA 99/1 sample with the experimental data $(\bullet)$, and the theoretical prediction (-).

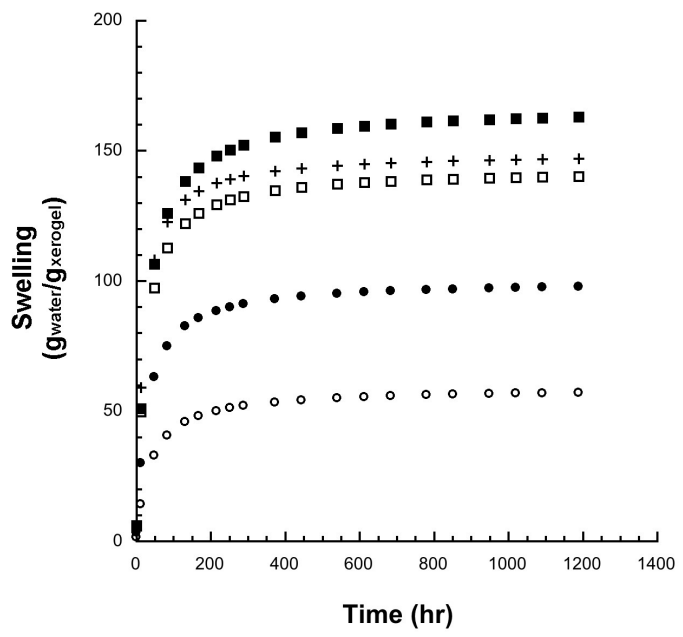

Figure 3. Swelling Kinetics of hydrogels depending on the proportion of NIPA/IA 99/1 (०), 98/2(•) 97/3(口) 96/4 (+) y 95/5 (ロ).

Table 1. Equilibrium swelling and kinetic data of the hidrogeles synthized at $4{ }^{\circ} \mathrm{C}$.

\begin{tabular}{|c|c|c|c|c|c|}
\hline NIPA/IA \% weight & $99 / 1$ & $98 / 2$ & $97 / 3$ & $96 / 4$ & $95 / 5$ \\
\hline Slope $(\mathrm{m})$ & 1.017 & 1.010 & 1.007 & 1.006 & 1.007 \\
\hline $\mathrm{H} \infty\left(\mathrm{g}_{\text {water }} / \mathrm{g}_{\text {xeroge }}\right)$ & 59.140 & 102.260 & 142.644 & 161.784 & 150.042 \\
\hline Dev std & 0.582 & 0.770 & 2.248 & 2.916 & 2.837 \\
\hline Intercept (b) & 38.374 & 16.810 & 9.426 & 9.780 & 7.331 \\
\hline $\mathrm{K} \mathrm{g}_{\text {hydrogel }} /\left(\mathrm{g}_{\text {water }}-\mathrm{min}\right)$ & 0.027 & 0.061 & 0.108 & 0.104 & 0.138 \\
\hline Transition temperature & $38^{\circ} \mathrm{C}$ & $42{ }^{\circ} \mathrm{C}$ & $44^{\circ} \mathrm{C}$ & $44^{\circ} \mathrm{C}$ & $44^{\circ} \mathrm{C}$ \\
\hline
\end{tabular}


has been observed that when the $\mathrm{pH}$ of the solution is regulated (adding $\mathrm{HCl}$ to obtain a $\mathrm{pH}$ of 3 ), the capacity of the hydrogels to absorb solution is seen to be reduced, owing to the fact that the acid groups are not ionized and, with this, the availability of spaces in the network

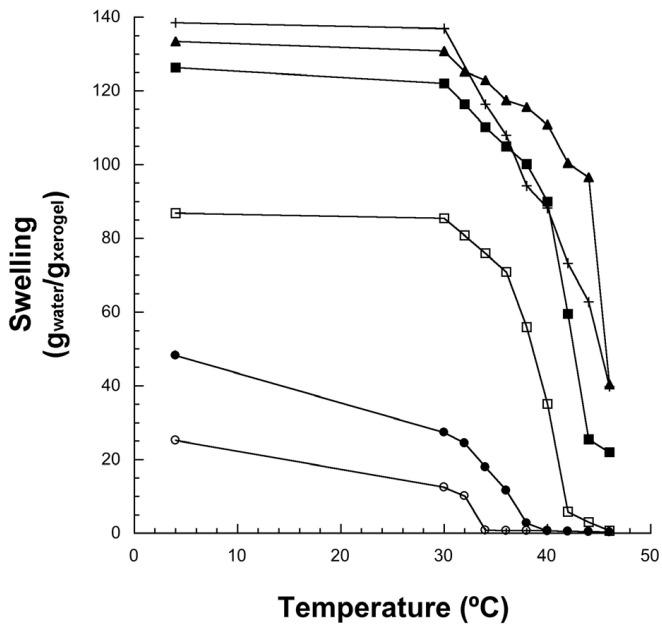

Figure 4. Equilibrium swelling in relation to temperature depending on the proportion of NIPA/IA 100/0 (०), 99/1 (•), 98/2 $(\square), 97 / 3(\boldsymbol{\bullet}), 96 / 4(+)$ and $95 / 5(\mathbf{\Delta})$. for the capture of water and metal ions is also reduced (Table 2). So it is known that increasing the temperature increases the solubility and therefore $\mathrm{Ni}^{2+}$ prefers to be in water and not in the hydrogel. Table 3 shows that on reducing the concentration of nickel ions in the solution, the capacity to absorb nickel solution is increased, as does the percentage of nickel ion removal, which corroborates that the presence of nickel ions reduces the active spaces for water absorbtion.

With this, the space is opened to develop the process of removing metal ions, firstly by placing the hydrogels in the nickel ion solutions. Then, when the hydrogels become saturated with the metal, they are removed from the medium and placed in solutions with a $\mathrm{pH}$ of 3 or more, and/or at temperatures greater than $40^{\circ} \mathrm{C}$, at which the metal ions will be displaced from the hydrogel. The use of this procedure was intended to obtain metal saturated solutions and to explore the possibility of reusing the hydrogels. To determine the magnitude of the degradation of the hydrogels, all the samples were placed in the solutions at $5 \%$ of $\mathrm{NiCl} 2$ at $4^{\circ} \mathrm{C}$ and, when they attained equilibrium swelling they were placed in a temperature controlled bath at $40{ }^{\circ} \mathrm{C}$ on four separate occasions. In all cases, similar swelling levels and $\mathrm{Ni}^{+2}$ ion absorbtion were obtained, with the loss of hydrogel mass determined in each experiment, which was less than $1 \%$ in all cases.

Table 2. Equilibrium swelling, mass of $\mathrm{Ni}^{+2}$ absorbed from the hydrogels when they are placed in $5 \% \mathrm{NiCl}_{2}$ solutions depending on the proportion of NIPA/IA at different temperatures and $\mathrm{pH}$ levels.

\begin{tabular}{cccccc}
\hline NIPA/IA \% weight & $\mathbf{1 0 0 / 0}$ & $\mathbf{9 9 / 1}$ & $\mathbf{9 5 / 5}$ & $\mathbf{9 0 / 1 0}$ & $\mathbf{8 5 / 1 5}$ \\
\hline $\mathrm{W}_{\infty}$ water $4{ }^{\circ} \mathrm{C}$ & 25.235 & 59.140 & 150.042 & 306.792 & 393.695 \\
$\mathrm{~W} \infty$ water $30^{\circ} \mathrm{C}$ & 13.165 & 27.35 & 130.820 & 249.482 & 265.648 \\
$\mathrm{~W} \infty$ water $40^{\circ} \mathrm{C}$ & 0.3950 & 0.60 & 110.81 & 207.680 & 227.276 \\
$\mathrm{~W} \infty \mathrm{Ni} 4{ }^{\circ} \mathrm{C}$ & 17.108 & 29.20 & 32.70 & 27.40 & 36.47 \\
$\mathrm{~W} \infty \mathrm{Ni} 30^{\circ} \mathrm{C}$ & 3.382 & 10.11 & 19.50 & 15.69 & 28.57 \\
$\mathrm{~W} \infty \mathrm{Ni} 40^{\circ} \mathrm{C}$ & 0.860 & 1.41 & 3.13 & 1.41 & 4.52 \\
$\mathrm{~g}_{\mathrm{Ni}} / \mathrm{g}_{\text {xerogel }} 4{ }^{\circ} \mathrm{C}$ & 0.318 & 0.645 & 0.77 & 0.88 & 1.201 \\
$\mathrm{~g}_{\mathrm{N}} / \mathrm{g}_{\text {xerogel }} 30^{\circ} \mathrm{C}$ & 0.175 & 0.210 & 0.55 & 0.41 & 0.20 \\
$\mathrm{~g}_{\mathrm{N}} / \mathrm{g}_{\text {xerogel }} 40^{\circ} \mathrm{C}$ & 0.05 & 0.069 & 0.139 & 26.593 & 0.608 \\
$\mathrm{~W}_{\infty} \mathrm{Ni} \mathrm{pH} 34{ }^{\circ} \mathrm{C}$ & - & 27.708 & 24.409 & 12.927 & 41.007 \\
$\mathrm{~W}_{\infty} \mathrm{Ni} \mathrm{pH} 330^{\circ} \mathrm{C}$ & - & 1.580 & 6.958 & 1.077 & 27.4334 \\
$\mathrm{~W}_{\infty} \mathrm{Ni} \mathrm{pH} 340^{\circ} \mathrm{C}$ & - & 0.622 & 2.120 & 1.358 & 2.566 \\
$\mathrm{~g}_{\mathrm{N}} / \mathrm{g}_{\text {xerogel }} 4{ }^{\circ} \mathrm{C}$ & - & 0.278 & 0.844 & 0.331 & 0.981 \\
$\mathrm{~g}_{\mathrm{Ni}} / \mathrm{g}_{\text {xerogel }} 30^{\circ} \mathrm{C}$ & - & 0.351 & 0.487 & 0.159 & 0.677 \\
$\mathrm{~g}_{\mathrm{Ni}} / \mathrm{g}_{\text {xerogel }} 40^{\circ} \mathrm{C}$ & - & 0.161 & 0.151 & & 0.142 \\
\hline
\end{tabular}

Table 3. Equilibrium swelling of the hydrogels for the NIPA/IA $85 / 15$ hydrogel, placed in $\mathrm{NiCl}_{2}$ solutions according to the salt concentration.

\begin{tabular}{|c|c|c|c|c|c|c|}
\hline \multirow{2}{*}{$\begin{array}{c}\text { Concentration } \\
\mathrm{NiCl}_{2}\end{array}$} & \multicolumn{2}{|c|}{$4^{\circ} \mathrm{C}$} & \multicolumn{2}{|c|}{$30^{\circ} \mathrm{C}$} & \multicolumn{2}{|c|}{$40^{\circ} \mathrm{C}$} \\
\hline & $\mathbf{W}$ & $\mathbf{g}_{\mathrm{Ni}} / \mathbf{g}_{\text {xerogel }}$ & $\mathbf{W}$ & $\mathbf{g}_{\mathrm{Ni}} / \mathbf{g}_{\text {xerogel }}$ & W & $\mathbf{g}_{\mathrm{Ni}} / \mathbf{g}_{\text {xerogel }}$ \\
\hline $3.000 \%$ & 30.956 & 1.429 & 22.388 & 1.205 & 12.012 & 0.380 \\
\hline $2.500 \%$ & 30.973 & 1.259 & 22.770 & 1.152 & 13.476 & 0.353 \\
\hline $1.000 \%$ & 32.092 & 0.500 & 24.513 & 0.417 & 17.293 & 0.138 \\
\hline $0.500 \%$ & 33.551 & 0.252 & 26.614 & 0.213 & 19.241 & 0.050 \\
\hline $0.350 \%$ & 52.757 & 0.215 & 42.153 & 0.142 & 31.578 & 0.018 \\
\hline $0.200 \%$ & 57.767 & 0.122 & 48.763 & 0.081 & 38.611 & 0.007 \\
\hline $0.100 \%$ & 71.048 & 0.090 & 57.933 & 0.028 & 48.558 & $<0.005$ \\
\hline
\end{tabular}




\section{Conclusions}

It was found that the addition if itaconic IA increased the capacity to absorb water. The capacity to absorb Ni ions was determined using aqueous $\mathrm{NiCl}_{2}$ solutions with a composition of $5 \%$. In all samples, the greatest capacity to absorb nickel was found at $4{ }^{\circ} \mathrm{C}$. The possible use of these materials was determined for the recovery of nickel from industrial effluent and its recovery as a raw material, on removing the nickel from the solution at low temperatures and subsequently subjecting the saturated hydrogel to high temperatures. The low temperature depends on the proportion of itaconic acid in the sample. We can, therefore, establish that a low temperature would be $4{ }^{\circ} \mathrm{C}$ for the hydrogels with a 1 to $4 \%$ acid content. A temperature of $30^{\circ} \mathrm{C}$ would be low for those hydrogels with a 5 to $15 \%$ acid content, these materials are left at this temperature to absorb the metal ions, with the loaded and saturated hydrogels then withdrawn from the medium and placed in the high temperatures, which would be $40{ }^{\circ} \mathrm{C}$ for the hydrogels with a low acid content and $46{ }^{\circ} \mathrm{C}$ for those hydrogels with a higher acid content. Small quantities of acid solution are added in order to obtain a $\mathrm{pH}$ value of between 1 and 3 in the medium.

\section{References}

1. Matlock, M. M., Howerton, B. S., \& Atwood, D. A. (2002). Chemical precipitation of heavy metals from acid mine drainage. Water Research, 36(19), 4757-4764. PMid:12448518. http:// dx.doi.org/10.1016/S0043-1354(02)00149-5.

2. Ito, A. (2000). Removal of heavy metals from anaerobically digested sewage sludge by a new chemical method using ferric sulfate. Water Research, 34(3), 751-758. http://dx.doi. org/10.1016/S0043-1354(99)00215-8.

3. Lefers, J. B., van den Broeke, W. F., Venderbosch, H. W., de Niet, J., \& Kettelarij, A. (1987). Heavy metal removal from waste water from wet lime(stone)-gypsum flue gas desulfurization plants. Water Research, 21(11), 1345-1354. http://dx.doi.org/10.1016/0043-1354(87)90008-X.

4. Cerón Neculpan, M. S. (2006). Remoción de cadmio presente en aguas de desecho de la industria metal-mecánica mediante membranas líquidas emulsificadas en extractores del tipo estanque agitado en proceso batch. (Tesis memoria para optar al titulo de químico). Universidad de Chile, Chile.

5. Huang, P., Ye, Z., Xie, W., Chen, Q., Li, J., Xu, Z., \& Yao, M. (2013). Rapid magnetic removal of aqueous heavy metals and their relevant mechanisms using nanoscale zero valent iron (nZVI) particles. Water Research, 12(47), 4050-4058. PMid:23566331. http://dx.doi.org/10.1016/j.watres.2013.01.054.

6. Xiang, L., Chan, L. C., \& Wong, J. W. (2000). Removal of heavy metals from anaerobically digested sewage sludge by isolated indigenous iron-oxidizing bacteria. Chemosphere, 41(1-2), 283-287. PMid:10819212. http://dx.doi.org/10.1016/ S0045-6535(99)00422-1.

7. Wu, Q., \& Tian, P. (2008). Adsorption of $\mathrm{Cu}^{+2}$ Ions with Poly (N-isopropylacrylamide-co-methacrylic acid) Micro/ Nanoparticles. Journal of Applied Polymer Science, 109(6), 3470-3476. http://dx.doi.org/10.1002/app.28450.

8. Bekiari, V., Sotiropoulou, M., Bokias, G., \& Lianos, P. (2008). Use of poly(N,N-dimethylacrylamide-co-sodium acrylate) hydrogel to extract cationic dyes and metals from water. Colloids and Surfaces A: Physicochemical and Engineering Aspects, 312(2-3), 214-218. http://dx.doi.org/10.1016/j. colsurfa.2007.06.053
9. Ozay, O., Ekici, S., Baran, Y., Aktas, N., \& Sahiner, N. (2009). Removal of toxic metal ions with magnetic hydrogels. Water Research, 43(17), 4403-4411. PMid:19625066. http://dx.doi. org/10.1016/j.watres.2009.06.058.

10. El Halah, A., Contreras, J., \& López, F. (2011). Síntesis y aplicaciones de hidrogeles superabsorbentes de poli(acrilamidaco-monoitaconato de metoxietilo). Revista Latinoamericana de Metalurgia y Materiales, S3, 30-31.

11. Yildiz, U., Kemik, O. F., \& Hazer, B. (2010). The removal of heavy metal ions from aqueous solutions by novel $\mathrm{pH}-$ sensitive hydrogels. Journal of Hazardous Materials, 183(13), 521-532. PMid:20709450. http://dx.doi.org/10.1016/j. jhazmat.2010.07.055.

12. Shibayama, M., Motonaga, T., \& Nakamoto, C. (2001). Preparation pressure dependence of structure Inhomogeneities and dynamic fluctuations in poly(N-isopropylacrylamide). Gels Macromolecules, 34(4), 911-911. http://dx.doi.org/10.1021/ ma001372v.

13. Biswas, C. S., Sulu, E., Hazer, B. (2014). Effect of the composition of methanol-water mixtures on tacticity of poly (N-ethylacrylamide) Gel Journal of Applied Polymer Science, 132, 41668-41678. http://dx.doi.org/10.1002/app.41668.

14. Biswas, C. S., \& Hazer, B. (2015). Synthesis and characterization of stereoregular poly(N-ethylacrylamide) hydrogel by using Y(OTf)3 Lewis acid. Colloid \& Polymer Science, 293(1), 143-152. http://dx.doi.org/10.1007/s00396-014-3399-1.

15. Cortés, J. A., Mendizábal, E., \& Katime, I. (2008). Effect of comonomer type and concentration on the equilibrium swelling and volume phase transition temperature of $\mathrm{N}$ isopropylacrylamide-based hydrogels. Journal of Applied Polymer Science, 108(3), 1792-1796. http://dx.doi.org/10.1002/ app.27632.

16. Ortega, J. A. C. (2013). Synthesis of thermosensitive hydrogels of poly(N-isopropylacrylamide)-co-poly(N,N-dimethylacrylamide). Polímeros: Ciência e Tecnologia, 23(2), 189-195. http://dx.doi. org/10.4322/polimeros.2013.080.

17. Yildı, U., \& Hazer, B. (2000). Dispersion redox copolymerization of methyl methacrylate with macromonomeric azoinitiator as a macro crosslinker. Polymer, 41(2), 539-544. http://dx.doi. org/10.1016/S0032-3861(99)00217-7.

18. Fernandez, V. V. A., Tepale, N., Sánchez-Díaz, J. C., Mendizábal, E., Puig, J. E., \& Soltero, J. F. A. (2006). Thermoresponsive nanostructured poly ( $\mathrm{N}$-isopropylacrylamide) hydrogels made via inverse microemulsion polymerization. Colloid \& Polymer Science, 284(4), 387-395. http://dx.doi.org/10.1007/s00396005-1395-1.

19. Katime, I., Velada, J. L., Novoa, R., Díaz de Apodaca, E., Puig, J., \& Mendizabal, E. (1996). Swelling kinetics of Poly(Acrilamide)/Poly(mono-n-alkyl Itaconates) hydrogels. Polymer International, 40(4), 281-286. http://dx.doi.org/10.1002/ (SICI)1097-0126(199608)40:4<281::AID-PI555>3.0.CO;2-H.

20. Bajpai, S. K., \& Johnson, S. (2007). Removal of $\mathrm{Ni}^{+2}$ ions from aqueous solution by sorption into Poly(Acrylamide-co-Sodium Acrylate) hydrogels. Journal of Macromolecular Science, Part A: Pure and Applied Chemistry, 44(3), 291-297. http://dx.doi. org/10.1080/10601320601077328.

21. Rojas de Gáscue, B., Ramírez, M., Prin, J.L., Torres, C., Bejarano, L., Villarroel, H., Rojas L., Murillo, M., \& Katime, I. (2010). Hidrogeles de acrilamida/ácido acrilico y de acrilamida/ poli(ácido acrilico): estudio de su capacidad de remediación en efluentes industriales. Revista Latinoamericana de Metalurgia y Materiales, 30(1), 28-39. 


\section{Supplementary Material}

Supplementary material accompanies this paper.

Figure s1. Fraction of water released from the hydrogels in relation to temperature as a function of the proportion of

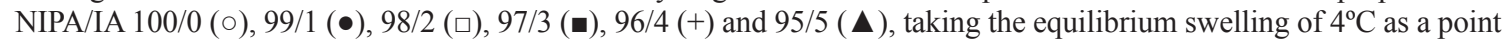
of reference.

Table s1. Change in the fraction released in relation to temperature, which was calculated using $\left(\mathrm{F} 32^{\circ} \mathrm{C}-\mathrm{F} 30^{\circ} \mathrm{C}\right) /$ $\left(32^{\circ} \mathrm{C}-30^{\circ} \mathrm{C}\right) 32^{\circ} \mathrm{C}$ and in the same manner for the rest of the temperatures.

This material is available as part of the online article from www.scielo.br/po 